\title{
Solid phase synthesis of biohybrid block copolymers
}

\author{
Irene C. Reynhout, Dennis W. P. M. Löwik, Jan C. M. van Hest, Jeroen J. L. M. Cornelissen* and \\ Roeland J. M. Nolte
}

Received (in Cambridge, UK) 14th September 2004, Accepted 21st October 2004

First published as an Advance Article on the web 8th December 2004

DOI: $10.1039 / \mathrm{b} 413973 \mathrm{a}$

\begin{abstract}
A new versatile route to synthesise biohybrid block copolymers is presented in which an amine terminated polymer is attached to an aldehyde functionalised resin, from which in subsequent steps the desired peptide can be grown using standard procedures.
\end{abstract}

Amphiphiles are an important class of compounds with interesting physical properties. Because of their broad range of applications, a lot of research towards the development of new types of amphiphilic compounds has been carried out. This has resulted not only in the classical low molecular weight amphiphiles, but also in new macromolecular architectures referred to as 'super amphiphiles' and 'giant amphiphiles'. ${ }^{1}$ The former type consists of two polymeric blocks, while the latter are built up from a polymer (e.g. polystyrene) as the nonpolar tail and a protein or enzyme as the polar head group. Various examples of super amphiphiles have been reported in recent literature. They are synthesised both from purely synthetic segments ${ }^{2}$ and from peptide (or peptide-like) blocks. ${ }^{3}$ Examples of giant amphiphiles are still limited; three different routes towards these macromolecules have been reported so far. ${ }^{4}$ The current challenge is to precisely control the structure, dimension and shape of the polymeric amphiphilic architectures in such a way that specific properties or functions can be obtained. This requires a substantial synthetic effort.

In search for a more versatile approach to polymeric biohybrid amphiphiles, with improved ease of purification, synthesis on a solid support was investigated. Synthesis of polymer-peptide block copolymers using solid phase procedures has been reported recently employing both nitroxide mediated polymerisation ${ }^{5}$ and $\mathrm{ATRP}^{6}$ for the preparation of the polymer segment. In these studies an amino acid sequence, in which at the terminus a polymerisation initiator is present, was synthesised on the resin. Subsequently, this initiator group was used to grow the second block on the resin. Here, a new route towards peptide-polymer amphiphiles is presented in which (nonpolar) amine functionalised polymers are first attached to the resin and subsequently used to synthesise the peptide part. ${ }^{7}$ Particularly in the case of polystyrene (PS), in principle, a large variety of amino acids can be introduced, still allowing excellent control over the molecular weight and polydispersity of the block copolymer. Recently Löwik et al. showed that it is possible, using an entirely solid support method to attach alkyl chains to both the C-and N-terminus of a $\beta$-turn sequence from the circumsporozoite (CS) protein of the malaria parasite, Plasmodium falciparum. The amino acid sequence in this peptide is glycine, alanine, asparagine, proline, asparagine, alanine, alanine and glycine (GANPNAAG). Double alkylation resulted in

*J.Cornelissen@science.ru.nl the stabilisation of the $\beta$-hairpin fold. ${ }^{8}$ Here, this strategy is extended to polystyrene chains to obtain biohybrid compounds 1 and 2 (Fig. 1).

The synthesis of the peptide-polymer amphiphiles is shown in Scheme 1. The amine functionalised polystyrene was prepared by anionic polymerization and coupling of a polar ethylene glycol spacer to the carboxylic acid end-group of the polymer using standard coupling procedures. ${ }^{4}$ Alternatively, aminated polymers could be prepared by using a Boc-protected amine functionalised initiator in an ATRP reaction. This also resulted in polymers with well-controlled molecular weight and a relatively narrow size distribution (PDI < 1.2). ${ }^{9}$

The amine functionalised polystyrene was attached to a commercially available aldehyde modified resin $\dagger$ in acetic acid and $\mathrm{MeOH} / \mathrm{DMF}(1: 9 \mathrm{v} / \mathrm{v})$ as the solvent mixture by means of a reductive amination. Sodium cyanoborohydride was used in order to reduce the imine bond. After washing the resin with DMF, $\mathrm{CH}_{2} \mathrm{Cl}_{2}$ and $\mathrm{Et}_{2} \mathrm{O}$, a chloranil test was carried out in order to check if coupling had occurred. This test was positive indicating a successful coupling reaction.

Fmoc protected glycine was the first amino acid that was coupled to the polymer functionalised resin. After $24 \mathrm{~h}$ the reaction was stopped. Negative Kaiser and chloranil tests were indicative of the successful introduction of this amino acid. To ensure that in subsequent reaction steps no longer free secondary amines were present, an endcapping reaction was carried out using acetic acid anhydride.

The next seven amino acids in the GANPNAAG sequence were coupled using standard peptide synthesis protocols (see Scheme 1). ${ }^{10}$ Each reaction step took $4 \mathrm{~h}$ to complete according to a Kaiser test ${ }^{11}$ (in the case of proline a chloranil test ${ }^{12}$ was performed to check completion), which indicated quantitative formation of the block copolymer. After cleavage from the resin
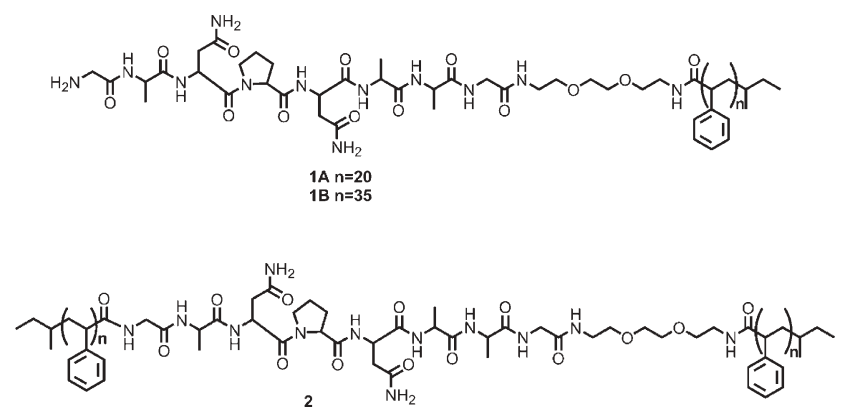

Fig. 1 Peptide-polymer block copolymers of polystyrene- $b$ GANPNAAG (1A and 1B) and polystyrene- $b$-GANPNAAG- $b$ polystyrene (2) 

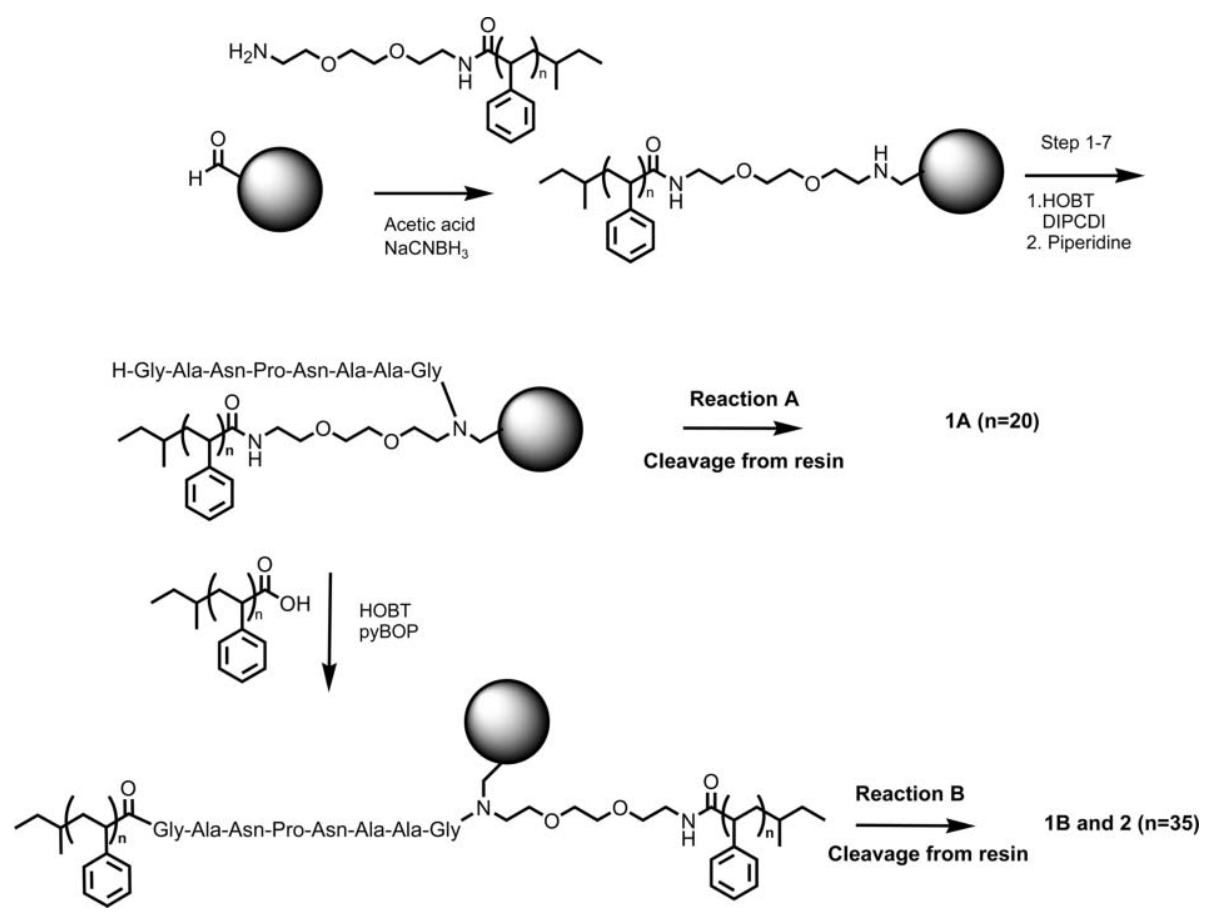

Scheme 1 Synthetic route towards peptide-polymers 1A, 1B and 2.

1A was isolated and characterised by GPC and NMR. After removal of an equal amount of end-capped polystyrene the product was obtained in $15 \%$ yield based on the initial loading of the resin. The relatively high amount of end-capped polystyrene can be explained by the tedious coupling of the first amino acid (glycine).

In order to prepare triblock copolymers, carboxylic acid functionalised polystyrene was reacted with the terminal amine of the peptide sequence on the resin. For this purpose $\mathrm{PS}_{35}$ instead of $\mathrm{PS}_{20}$ was used because it was observed that after cleavage of $\mathbf{1 A}$ from the resin, isolation of the biohybrid was complicated due to the amphiphilic character of this molecule. The coupling of the carboxylic acid functionalised polystyrene appeared to proceed relatively slowly, as expected due to the increased steric bulk of the macromolecular reagents; after $24 \mathrm{~h}$ the positive Kaiser test still revealed the presence of some free amines, even when using a more reactive coupling agent, i.e. pyBOP and DIPEA.

GPC and MALDI-TOF mass spectrometry experiments showed that in reaction B after cleavage from the resin, a mixture of three products was obtained; i.e. end-capped polystyrene, PS$b$-GANPNAAG (1B) and PS- $b$-GANPNAAG- $b$-PS (2). ${ }^{13}$ These products could be purified by column chromatography using $\mathrm{MeOH} / \mathrm{CH}_{2} \mathrm{Cl}_{2}(1: 9 \mathrm{v} / \mathrm{v})$ as an eluent. As expected, based on the polarity, end-capped polystyrene eluted first, followed by $\mathbf{2}$. As the final product the diblock copolymer $\mathbf{1 B}$ was obtained in pure form. The obtained product composition indicates that, after the first glycine coupling step, peptide synthesis on the polystyrene modified resin was not hampered for both $\mathrm{PS}_{20}$ and $\mathrm{PS}_{35}$. It was evident from GPC (Fig. 2, trace c) that triblock copolymer $\mathbf{2}$ could be prepared. This opens the possibility to prepare $\mathrm{ABC}$ triblock copolymers containing a peptide middle block.

The decrease in elution time in going from the polystyrene derivative to $\mathbf{1 B}$, points to an increase of the molecular weight. Relative to polystyrene standards no absolute MW can be given,

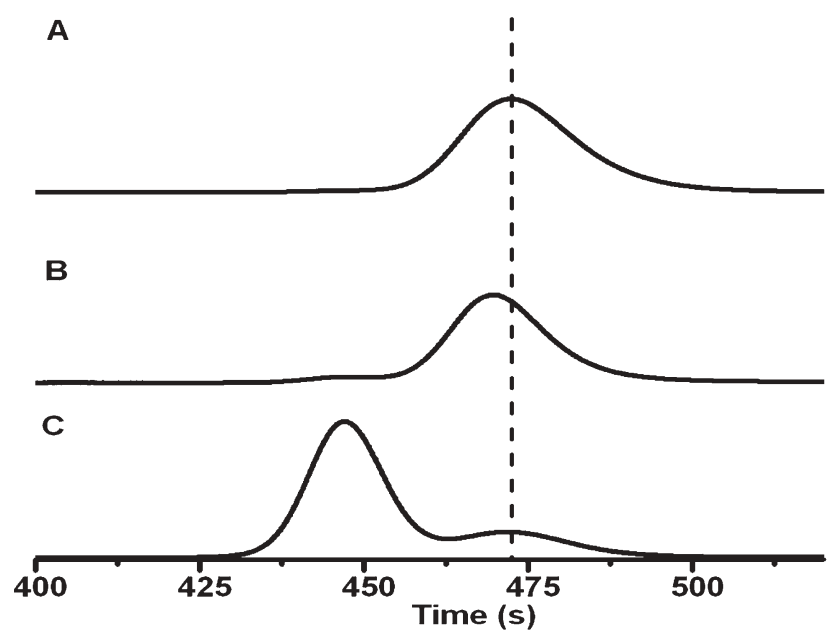

Fig. 2 GPC data (THF is used as eluent): End-capped polystyrene, $M_{\mathrm{n}}=3529$, DPI $=1.06\left(\right.$ trace A); PS- $b$-GANPNAAG, $M_{\mathrm{n}}=4164$, DPI $=1.07$ (trace B) and PS- $b$-GANPNAAG- $b$-PS, $M_{\mathrm{n}}=8952$, DPI $=1.04$ (trace $\mathrm{C}$, after a single chromatographic run this sample still contained minor amounts of PS homopolymer).

but end group analysis of MALDI TOF measurements strongly pointed to the formation of $\mathbf{1 B}$. For $\mathbf{2}$ a significantly higher molecular weight was found, confirming the formation of a triblock copolymer. Independently, the combination of the peptide segment and the polystyrene part in $\mathbf{1 B}$ could be proven by UV-vis and ${ }^{1} \mathrm{H}$ NMR spectroscopy.

Initial aggregation studies of PS- $b$-GANPNAAG (1B) were carried out by dispersing a THF solution in water. When $0.5 \mathrm{ml}$ of a $0.5 \mathrm{~g} \mathrm{~L}^{-1}$ THF solution of $\mathbf{1 B}$ was injected in $2.5 \mathrm{ml}$ of MilliQ water, aggregates which were likely to be micellar in nature were formed (Fig. 3A). These aggregates were quite uniform in size as was concluded from the histogram shown in Fig. 3B. After 4 

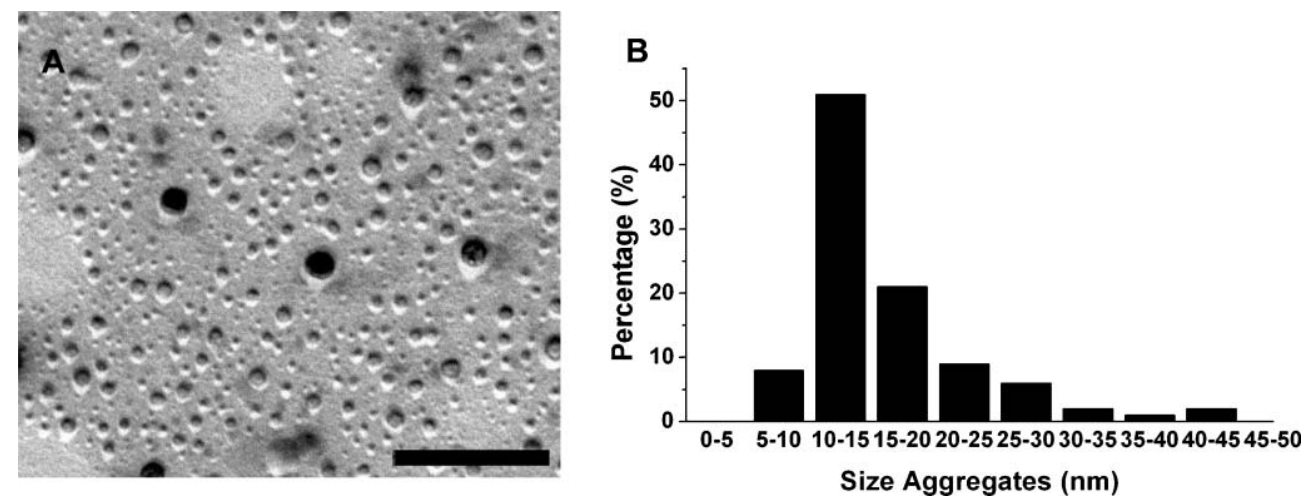

Fig. 3 (a) Aggregates formed by PS-b-GANPNAAG in water. The bar represents $200 \mathrm{~nm}$, (b) size distribution of spherical aggregates shown in Fig. $3 \mathrm{a}$ (number fraction)

months the solution was still turbid. TEM measurements showed that the micellar aggregates had transformed into larger spherical aggregates $(D \geqslant 250 \mathrm{~nm}$, probably vesicles).

We have shown that biohybrid block copolymers can be synthesised using straightforward solid-phase chemistry. In the presented procedure the synthetic polymer (polystyrene is used as an example) is connected to the resin first and subsequently the peptide sequence is introduced. In this way two different types of blocks can be coupled which would be difficult when carried out in solution. This allows good control over the molecular weight and polydispersity of the block copolymer segments, which contrasts to previously reported resin-based procedures. ${ }^{5,6}$ The large choice of synthetic polymers, in combination with the availability of large libraries of bio-relevant peptide sequences, has the potential to lead to a variety of new amphiphilic macromolecules with diverse and controllable functions. Furthermore, with the possibility to increase the complexity of the synthesised peptide segment the here described approach represents a synthetic route towards more complex peptide-polymer amphiphiles.

Part of this research was financially supported by the Council for the Chemical Sciences of the Netherlands Organization for Scientific Research (CW-NWO).

Irene C. Reynhout, Dennis W. P. M. Löwik, Jan C. M. van Hest, Jeroen J. L. M. Cornelissen* and Roeland J. M. Nolte

Department of Organic Chemistry, Institute for Molecules and Materials, Radboud University Nijmegen, Toernooiveld 1, 6525 ED,

Nijmegen, The Netherlands. E-mail: J.Cornelissen@science.ru.nl;

Fax: (+31) 24365 2929; Tel: (+31) 243652381

\section{Notes and references}

$\uparrow$ Aldehyde functionalised resin was purchased from Novabiochem. All other chemicals were purchased from Fluka and were used as received.
1 J. A. A. W. Elemans, A. E. Rowan and R. J. M. Nolte, J. Mater. Chem., 2003, 13, 2661; D. W. P. M. Löwik and J. C. M. van Hest, Chem. Soc. Rev., 2004, 33, 234.

2 For recent overviews see: D. E. Discher and A. Eisenberg, Science, 2002, 297, 967; M. Antonietti and S. Förster, Adv. Mater., 2003, 15, 1323; J. A. Opsteen, J. J. L. M. Cornelissen and J. C. M. van Hest, Pure Appl. Chem., 2004, 76, 1309.

3 H. Kukula, H. Schlaad, M. Antonietti and S. Förster, J. Am. Chem. Soc., 2002, 124, 1658; F. Chécot, S. Lecommandoux, Y. Gnanou and H.-A. Klok, Angew. Chem. Int. Ed., 2002, 41, 1339-1343; H.-A. Klok, Angew. Chem. Int. Ed., 2002, 41, 1509-1513; J. J. L. M. Cornelissen, M. Fischer, N. A. J. M. Sommerdijk and R. J. M. Nolte, Science, 1998, 280, 1427.

4 M. J. Boerakker, J. M. Hannink, P. H. H. Bomans, P. H. Frederik, R. J. M. Nolte, E. M. Meijer and N. A. J. M. Sommerdijk, Angew. Chem. Int. Ed., 2002, 41, 4239; J. M. Hannink, J. J. L. M. Cornelissen, J. A. Farrera, P. Foubert, F. C. de Schryver, N. A. J. M. Sommerdijk and R. J. M. Nolte, Angew. Chem. Int. Ed., 2001, 40, 4732; K. Velonia, A. E. Rowan and R. J. M. Nolte, J. Am. Chem. Soc., 2002, 124, 4224.

5 M. L. Becker, J. Q. Lui and K. L. Wooley, Chem. Commun., 2003, 180.

6 Y. Mei, K. L. Beers, H. C. M. Byrd, D. L. VanderHart and N. R. Washburn, J. Am. Chem. Soc., 2004, 126, 3472.

7 Non-amphiphilic biohybrid block copolymers have been prepared using N-terminus modification. G. W. M. Vandermeulen, C. Tziatzios and H.-A. Klok, Macromolecules, 2003, 36, 4107; A. Rösler, H.-A. Klok, I. W. Hamley, V. Castelletto and O. O. Mykhaylyk, Biomacromolecules, 2003, 4, 859; M. Pechar, P. Kopečková, L. Joss and J. Kopeček, Macromol. Biosci., 2002, 2, 199.

8 D. W. P. M. Löwik, J. G. Linhardt, P. J. H. M. Adams and J. C. M. van Hest, Org. Bioorg. Chem., 2003, 1, 1827.

9 I. C. Reynhout, R. Maeso Naval, J. J. L. M. Cornelissen and R. J. M. Nolte, unpublished results.

10 E. Atherton and R. C. Sheppard, Solid Phase Peptide Synthesis, IRL Press, Oxford, 1989; G. B. Fields and R. L. Noble, Int. J. Pept. Protein Res., 1990, 35, 161.

11 E. Kaiser, R. L. Colescot, C. D. Bossinge and P. I. Cook, Anal. Biochem., 1970, 34, 595.

12 T. Vojkovsky, Pept. Res., 1995, 8, 236.

13 Estimated product composition: end capped PS: 25\%, 1B: $65 \%$ and 2: $10 \%$. 